\title{
Prenatal genetic analysis and differential pregnancy outcomes of two de novo cases showing mosaic isodicentric Y chromosome
}

\author{
Si He${ }^{\dagger}$, Hui Xi ${ }^{\dagger}$, Jing Chen, Dan Wang, Jialun Pang, Jiancheng Hu, Qin Liu, Zhengjun Jia and Hua Wang*
}

\begin{abstract}
Background: Fetal cells collected from the amniotic fluid of two pregnant women indicated sex chromosome abnormalities. Therefore, we performed G-banded chromosome karyotype analysis, single nucleotide polymorphism array (SNP array), fluorescence in situ hybridization (FISH), and sequence-tagged sites (STS) analysis of the $Y$ chromosome to determine the rare molecular genetics of the two fetuses.

Case presentation: The karyotypes of the fetuses from patients 1 and 2 were mos 45,X[92]/46,X, $+\operatorname{idic}(Y)(q 11.21)[8]$ and mos 45,X[20]/46,X,+idic(Y)(q11.223)[80], respectively. Fetus 1 had a $7.76 \mathrm{Mb}$ deletion in Yq11.222q11.23 and a $15.68 \mathrm{Mb}$ duplication in Yp11.2q11.21. Fetus 2 had $21 \mathrm{Mb}$ of repetitive segments in Yp11.3q11.223. Azoospermia factor (AZF) detection by STS analysis revealed a missing AZFb+C region in fetus 1 and three functional AZF regions in fetus 2. The isodicentric $Y$ chromosome (idic (Y)) in both fetuses arose de novo. The pregnancy of patient 1 was terminated, whereas the fetus of patient 2 was delivered and is now 10 months old with normal appearance and growth.
\end{abstract}

Conclusion: A combination of technologies such as chromosome karyotyping, FISH, SNP arrays, and STS analysis of the $\mathrm{Y}$ chromosome is important in prenatal diagnosis to reduce birth defect rates and improve the health of the Chinese population.

Keywords: Isodicentric Y, AZF gene, SNP array

\section{Introduction}

Sex chromosome abnormalities account for $\sim 0.71 \%[1]$ of all prenatal diagnoses and can cause fetal gonadal dysgenesis, structural and functional abnormalities of other organs, and mental retardation or disorders [2]. The two fetuses in this study were both prenatally diagnosed as having sex chromosome abnormalities; both had only one $\mathrm{X}$ chromosome, and one additional small supernumerary marker chromosome (sSMC) with an unknown structure was found in some karyotypes. We confirmed a diagnosis using G-banded chromosome karyotyping, SNP arrays, FISH, and STS analysis of the Y chromosomes. A comparison with parental chromosomes confirmed that the form of the sSMC in both fetuses was an isodicentric $Y$

\footnotetext{
* Correspondence: wanghua213@aliyun.com

Si He and Hui Xi are Co-first author.

The prenatal diagnosis center of Hunan Province, The Maternal and Child

Health Hospital of Hunan Province, 53 Xiangchun Road, Kaifu District,

Changsha City, Hunan Province, China
}

chromosome (idic $[\mathrm{Y}]$ ) that had arisen de novo. Furthermore, fetus 1 had no AZF $\mathrm{b}+\mathrm{c}$ region and fetus 2 did not have an AZF deletion.

Idic $(\mathrm{Y})$ is clinically rare, and the clinical phenotype of patients with idic $(\mathrm{Y})$ is determined based on factors such as the breakpoint of the $\mathrm{Y}$ chromosome, the proportion of idic $(\mathrm{Y})$ cell lines in the gonads and other tissues, and the presence of the SRY and AZF genes. Ultrasound showed male external genitalia [3] in both fetuses herein, but idic $(\mathrm{Y})$ is associated with male gonadal dysgenesis and dyszoospermia [4, 5]. Therefore, whether the two fetuses would develop such issues postnatally was important to determine. The AZF region of the Y chromosome comprises the subregions AZFa, AZFb, and AZFc, the deletion of one or more of which, leads to dyszoospermia. After genetic counseling provided by Hunan Provincial Maternal and Child Health Care Hospital, the two pregnancies had different outcomes. One was terminated, whereas the

(c) The Author(s). 2020 Open Access This article is distributed under the terms of the Creative Commons Attribution 4.0 International License (http://creativecommons.org/licenses/by/4.0/), which permits unrestricted use, distribution, and reproduction in any medium, provided you give appropriate credit to the original author(s) and the source, provide a link to the Creative Commons license, and indicate if changes were made. The Creative Commons Public Domain Dedication waiver (http://creativecommons.org/publicdomain/zero/1.0/) applies to the data made available in this article, unless otherwise stated. 
other was carried to term. Here we describe the details of these pregnancies.

\section{Case presentation \\ Patients}

We describe two pregnant women who required prenatal diagnosis. Patient 1 was aged 22 years, and was G1P0. First- and second-trimester screens for Down syndrome revealed that her fetus was at critical risk. Each of her three noninvasive prenatal tests failed. Ultrasound during early pregnancy displayed a nuchal translucency of 1.7 $\mathrm{mm}$ and a crown-rump length of $48 \mathrm{~mm}$, and repeated ultrasound at 24 weeks of gestation revealed that her fetus had a slightly wide posterior cranial fossa $(10.4 \mathrm{~mm})$, which MRI later confirmed was $15.3 \mathrm{~mm}$, and the cisterna magna was not excluded.

Patient 2 was aged 32 years, G2P0, with one spontaneously aborted fetus that was not genetically analyzed. A second-trimester screen for Down syndrome, revealed high risk (1/146). Four-dimensional B-ultrasound did not detect any abnormalities.

\section{Methods}

\section{Sample collection}

Both patients provided written informed consent to the transabdominal collection of $40 \mathrm{~mL}$ (4 tubes) of amniotic fluids.

\section{G-banded chromosome karyotyping}

G-banded chromosomes were prepared from general cultures of amniotic fluid cells. We counted 100 metaphase cells and analyzed 10 karyotypes using ZEISS MetaClient (Carl Zeiss Microscopy, Oberkochen, Germany). The karyotypes are described according to the standards of the International System for Human Cytogenomic Nomenclature (ISCN 2016). Partial cell suspensions were stored at $-20^{\circ} \mathrm{C}$.

\section{Single nucleotide polymorphisms arrays}

We used Affymetrix CytoScan $750 \mathrm{~K}$ array chips incorporating 200,000 SNP markers and 500,000 copy number variation $(\mathrm{CNV})$ markers that are distributed across the human genome at an average density of about 1 marker/4 $\mathrm{kb}$. The arrays were run strictly according to the manufacturer's protocol and analyzed using the Chromosome Analysis Suite. Results were interpreted with reference to public databases including the hg19 human genome, the Database of Genomic Variants (DGV), the Database of Chromosomal Imbalance and Phenotype in Humans using Ensembl Resources (DECIPHER), the Online Mendelian Inheritance in Man (OMIM), the University of California, Santa Cruz (UCSC) Genome Browser and PubMed.

\section{Fluorescence in situ hybridization}

Fluorescence in situ hybridization proceeded using AneuVysion Multicolor DNA Probe Kits. A multicolor probe panel containing CEP 18 (white), X (green), and Y (orange) was used to detect $\alpha$-satellite repeats of the centrioles of chromosomes $\mathrm{X}$ and $\mathrm{Y}$, with normalization to the white signal of chromosome 18 . Hybridization signals from chromosomes in these cells were quantified using a Leica Imaging System fluorescence microscope.

\section{Sequence-tagged sites of the $\mathrm{Y}$ chromosome}

Deletions in the AZFa, AZFb, and AZFc regions of the Y chromosome were detected using Y Chromosome Microdeletions Detection Kits (Amoy Diagnostics Co., Ltd., Xiamen, Fujian, China), and the results were interpreted in strict accordance with the standards manual. Each subregion encompassed two STS; AZFa comprised Y84 and sY86, AZFb comprised sYl27 and sYl34, and AZFc comprised sY254 and sY255. The internal references were SRY and $\mathrm{ZFX} / \mathrm{Y}$.

\section{Results}

\section{Cytogenetics and molecular cytogenetics}

The fetuses with sSMC (Table 1) were investigated using cytogenetic and molecular cytogenetic means. The chromosome karyotypes of fetuses 1 and 2 were respectively, mos 45,X[92]/46,X,+mar[8] (Fig. 1a and b), and mos 45,X[20]/ 46,X,+mar[80] (Fig. 1c and d).

The SNP array detected a deletion of $7.76 \mathrm{Mb}$ in Yq11.222q11.23 of Case 1, In addition, fetus 1 had a

Table 1 Results of two fetuses with sSMC

\begin{tabular}{|c|c|c|}
\hline Fetus No. & Fetus 1 & Fetus 2 \\
\hline Karyotyping & $\operatorname{mos} 45, \mathrm{X}[92] / 46, \mathrm{X},+\operatorname{idic}(\mathrm{Y})[8]$ & $\operatorname{mos} 45, X[20] / 46, X,+\operatorname{idic}(Y)[80]$ \\
\hline SNP Array & $\begin{array}{l}\text { 7.76 Mb deletion in Yq11.222q11.23; } 15.68 \mathrm{Mb} \text { duplication in } \\
\text { Yp11.2q11.21 }\end{array}$ & $21 \mathrm{Mb}$ repetition in Yp11.3q11.223 \\
\hline FISH & mos nuc ish(DXZl×1,DYZ3 ×0)[178]/(DXZl×1, DYZ3×2)[22] & mos nuc ish(DXZ|x1,DYZ3×0)[38]/ (DXZIX1, DYZ3×2)[162] \\
\hline AZF & $\mathrm{AZFa}(+) \mathrm{AZFb}+\mathrm{C}(-)$ & $\mathrm{AZFa}+\mathrm{b}+\mathrm{c}(+)$ \\
\hline $\begin{array}{l}\text { Parental } \\
\text { comparison }\end{array}$ & $(-)$ & $(-)$ \\
\hline Outcome & Pregnancy terminated by no fetal examination. & $\begin{array}{l}\text { Normal male born with normal development at } 10 \text { months } \\
\text { of age }\end{array}$ \\
\hline
\end{tabular}




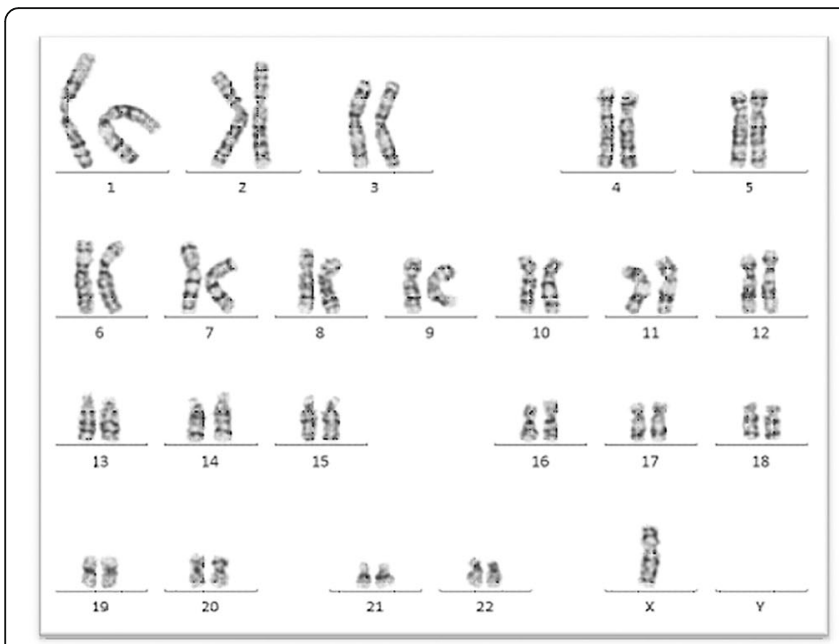

(a) $45, x$

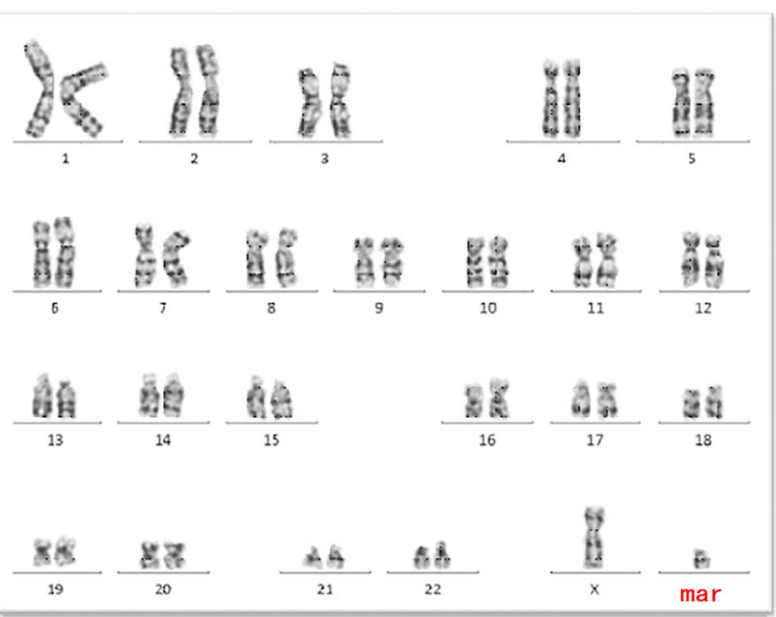

(b) $46, x,+$ mar

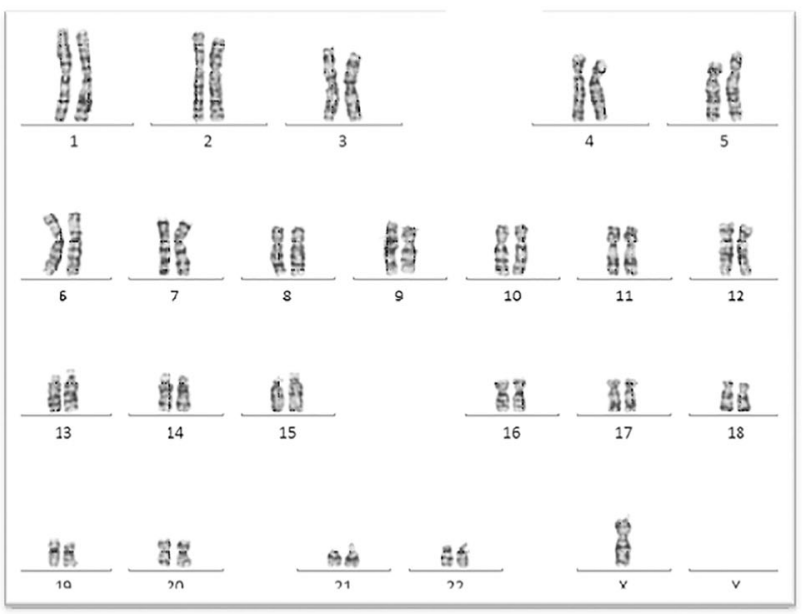

(c) $45, x$

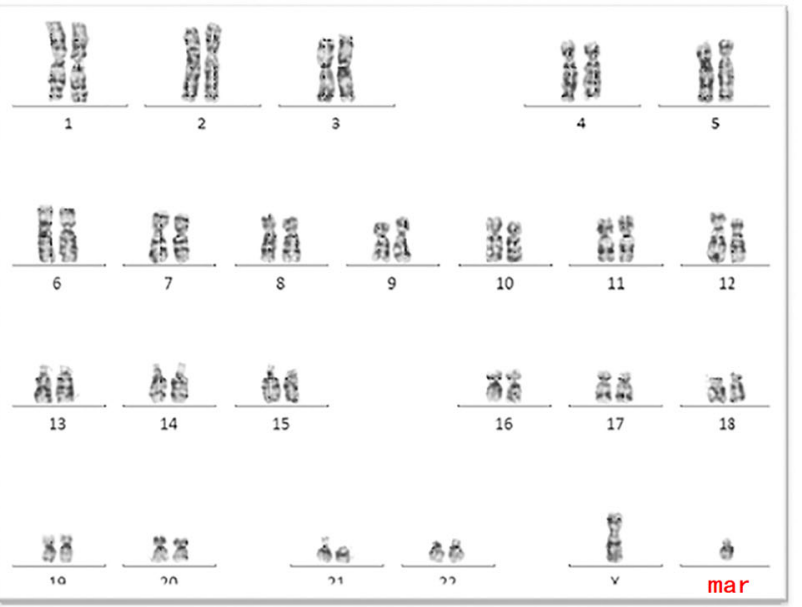

(d) 46, $X,+$ mar

Fig. 1 G-banded chromosome karyotyping. Fetus 1: 1a:45,X; 1b:46,X,+mar (a and b). Fetus 2: 1c:45,X; 1d:46,X,+mar (c and d). Both karyotypes are chimeras

duplication of $15.68 \mathrm{Mb}$ in Yp11.2q11.21. However, reports describing pathogenicity were not found in the ClinGen CNV or DGV databases. A few reports describing pathogenicity with uncertain significance were found in DECIPHER. Fetus 1 had further paternally inherited, autosomal mixed deletions spanning $0.57 \mathrm{Mb}$ at 6q16.2 (Fig. 2a). Approximately $21 \mathrm{Mb}$ were duplicated in Yp11.3q11.223 of fetus 2 . However, reports of pathogenicity were not found in ClinGen CNV, DGV or DECIPHER (Fig. 2b).

The chimeric ratio determined by FISH was consistent with that the karyotypes. In the interphase cells of both fetuses, all green DXZl probes for the pericentromeric region of the $\mathrm{X}$ chromosome displayed one hybridization signal, whereas the orange DYZ3 probes for the pericentromeric region of the $\mathrm{Y}$ chromosome displayed either two or no hybridization signals. The results of metaphase cells were the same for both fetuses. The two hybridization signals originating from the orange DYZ3 probes were derived from the same small chromosome. The results of fetuses 1 and 2 were respectively, mos nuc ish(DXZl $\times 1$, DYZ3 $\times 0)[178] /(D X Z l \times 1, \quad D Y Z 3 \times 2)[22]$ and mos nuc ish $(\mathrm{DXZl} \times 1, \mathrm{DYZ3} \times 0)[38] /(\mathrm{DXZl} \times 1, \mathrm{DYZ3} \times 2)[162]$ (Fig. 3).

\section{Detection of $Y$ chromosome microdeletions}

Fetus 1 contained the SRY and AZFa regions but lacked the $A Z F b+c$ region (Fig. 4a), whereas fetus 2 had all functional regions of SRY and AZF (Fig. 4b).

\section{Ultrasound and comparisons with parental chromosomes}

Ultrasound imaging revealed that both fetuses possessed male external genitalia. The parental chromosomes did not have any abnormalities associated with idic (Y). 


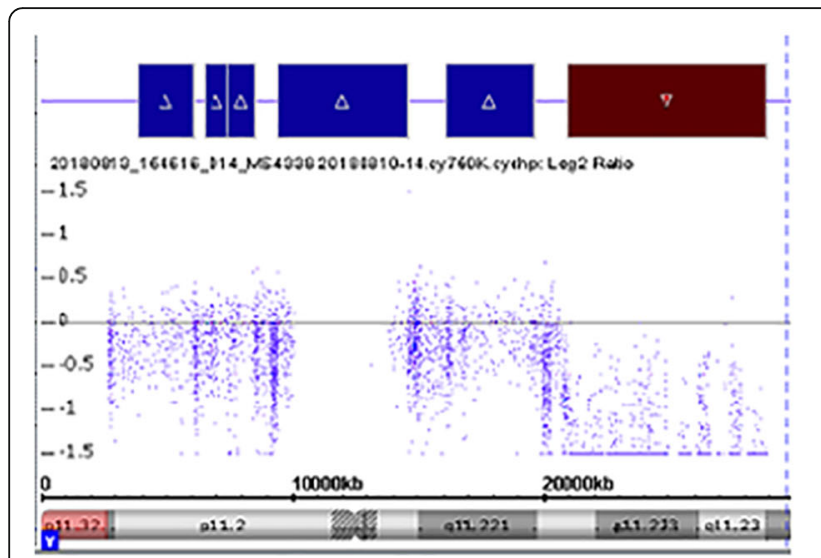

(a)

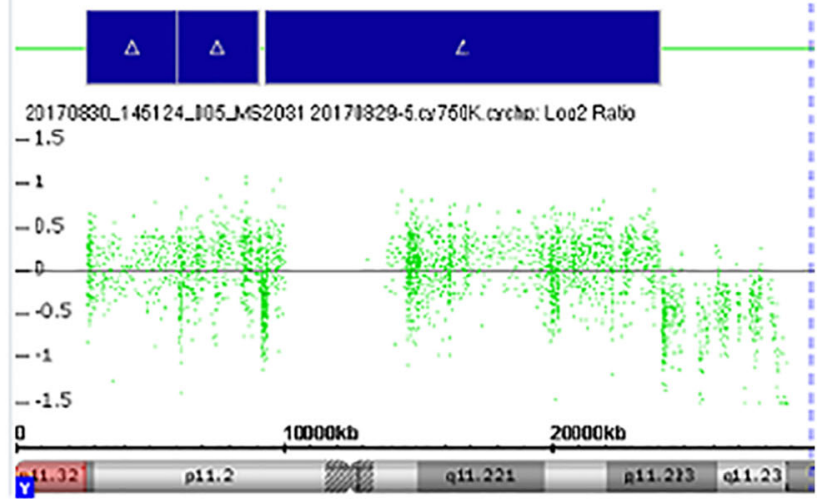

(b)

Fig. 2 Single nucleotide polymorphism array findings. Red part of fetus 1 (a) indicates $7.76 \mathrm{Mb}$ deletion in Yq11.222q11.23; blue part shows 15.68 $\mathrm{Mb}$ repeat in Yp11.2q11.21. Blue part of fetus 2 (b) shows $\sim 21 \mathrm{Mb}$ repeat in Yp11.3q11.223

\section{Comprehensive analysis}

The above results indicated that both mar carried by the two fetuses were de novo idic $(\mathrm{Y})$. The chromosome karyotypes of fetuses 1 and 2 were respectively, mos 45 , $\mathrm{X}[92] / 46, \mathrm{X},+\mathrm{idic}(\mathrm{Y})(\mathrm{q} 11.21)[8]$ and mos 45,X[20]/46,X,+ $\operatorname{idic}(\mathrm{Y})(\mathrm{q} 11.223)[80]$.

\section{Discussion and conclusions}

Chromosome karyotyping identified sSMC in two fetuses. The incidences of sSMC identified prenatally, among live births and among patients with developmental disorders are $0.4-1.5 \%, 0.14-0.72 \%$, and $0.288 \%$, respectively. Different origins of sSMC can lead to dicentric, circular, and small segment chromosomes with one centromere [6]. Most sSMC are derived from a gonosome, and some can be derived from an autosomes [7]. Small SMC derived from autosomes mainly form circular chromosomes, followed by small-segment, and a few dicentric chromosomes. Liehr et al. found that 72.6, 27, and $0.4 \%$ of sSMC are derived from $\mathrm{Y}$ chromosomes, $\mathrm{X}$ chromosomes, and autosomes, respectively [8]. The sSMC derived from Y chromosomes respectively present frequently and occasionally as small
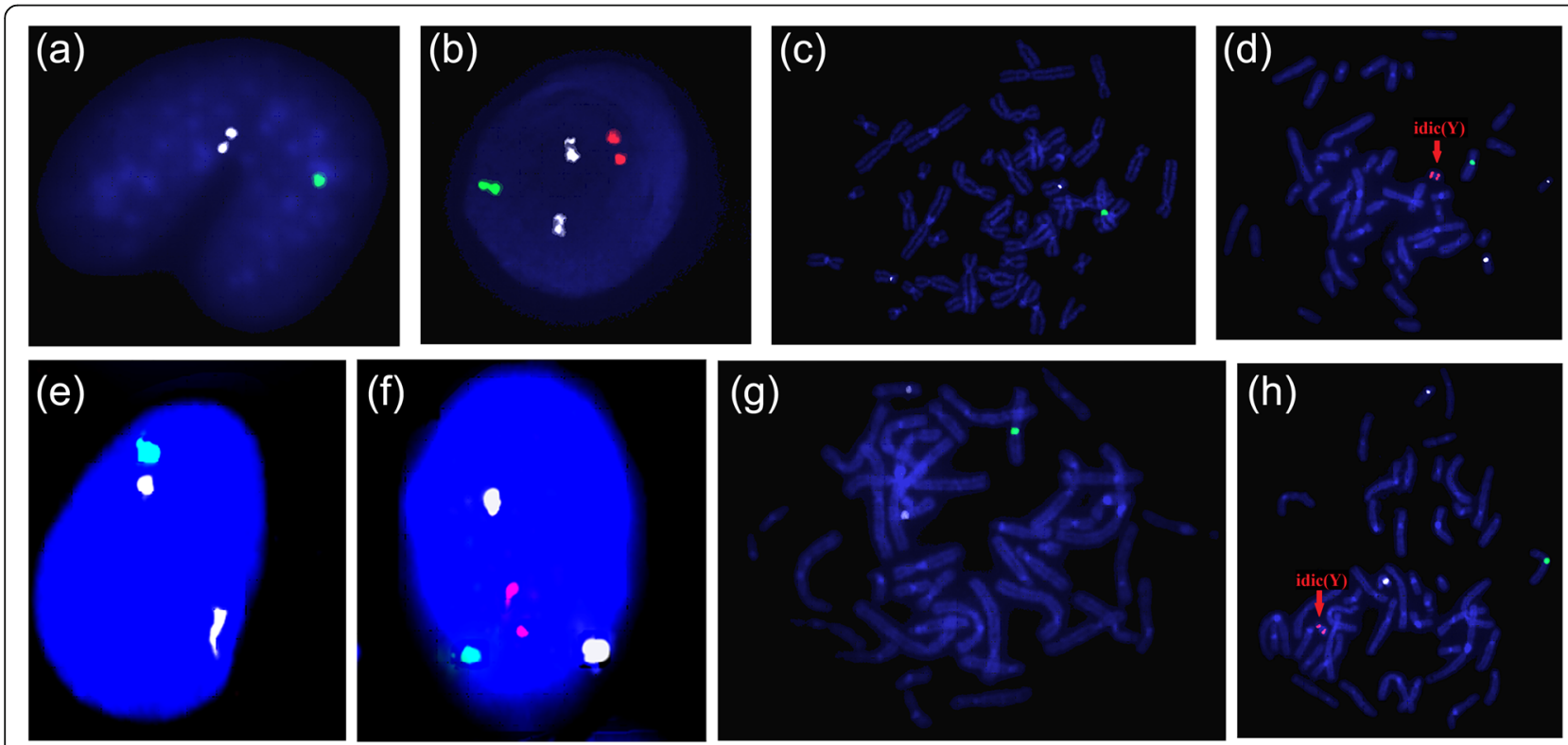

Fig. 3 Fluorescence in situ hybridization findings. CEP18 (white) $/ X$ (green) $/ Y$ (orange) with white signal chromosome 18 as reference. Fetus 1 : One $X$ centromeric signal in interphase (a); one $X$ centromeric signal and two $Y$ centromeric signals in interphase (b); one $X$ chromosome in metaphase (c); one $X$ chromosome and one dicentric $Y$ chromosome in metaphase (d). Fetus 2. One $X$ centromeric signal in interphase (e); one $X$ centromeric signal and two $Y$ centromeric signals in interphase $(\mathbf{f})$; one $X$ chromosome in metaphase $(\mathbf{g})$; one $X$ chromosome and one dicentric $Y$ chromosome in metaphase (h). Both fetal karyotypes are chimeras 


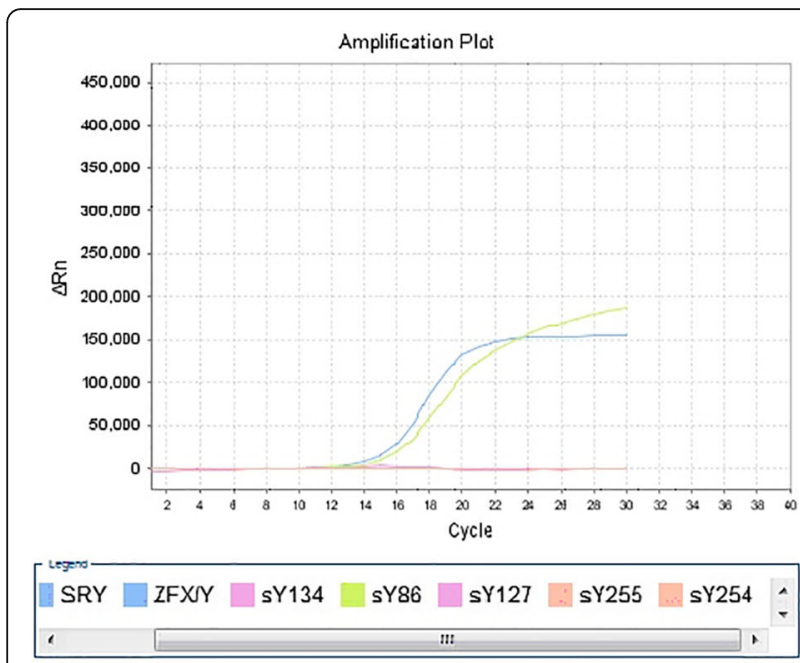

(a)

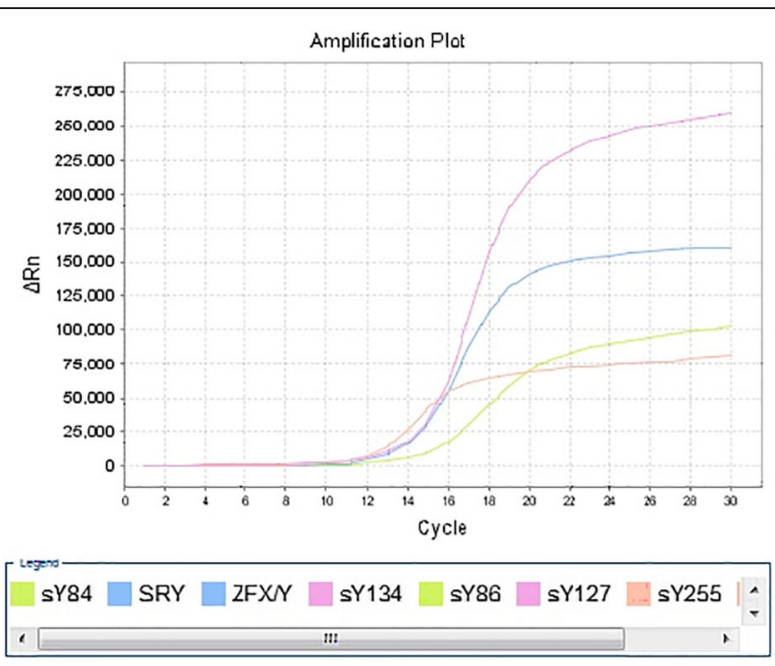

(b)

Fig. 4 Detection of $Y$ chromosome microdeletions. S-shaped amplification curve of loci of internal references ZFX/Y, sY84 and sY86 in fetus 1 show AZFa region and missing AZFb+C region (a). S-shaped amplification curves of all loci in fetus 2, which indicates that AZF showed no deletion (b).

segment and circular chromosomes. The underlying mechanism through which these sSMC are formed remains unclear.

Since sSMC have no characteristic bands, and traditional chromosome banding techniques cannot recognize its source or characteristics, a combination of multiple detection technologies is needed for analysis $[9,10]$. The SNP array revealed a $7.76 \mathrm{Mb}$ deletion in Yq11.222q11.23 and a $15.68 \mathrm{Mb}$ duplication in Yp11.2q11.21 of fetus 1 and approximately $21 \mathrm{Mb}$ of repetitive segments in Yp11.3q11.223 of fetus 2. These data indicated that the SSMC originated from $\mathrm{Y}$ chromosomes in both fetuses. Therefore, the repetitive segments might be idic $(\mathrm{Y})$. The FISH results showed that the sSMC of both fetuses had two Y centromeric signals, which further suggested that the sSMC forms were idic $(\mathrm{Y})$. However, the mechanism of idic $(\mathrm{Y})$ formation remains unclear. The popular belief is that when the sister chromatid of $\mathrm{Y}$ is separated during mitosis, cleavage occurs in regions of palindromes or inverted repeats. After the homologous exchange of sister chromatids, the cleavage site fuses to form idic (Y). Chromosomal segments without centromeres are degraded [11]. The karyotypes of both fetuses were chimeras that might have developed due to the instability of idic $(\mathrm{Y})$, which is often lost in mitosis, and the subsequent formation of $45, \mathrm{X}$ cells by $46, \mathrm{X}$, idic $(\mathrm{Y})$ cells. Most Y chromosome abnormalities are inherited paternally, and comparisons of paternal and fetal chromosomes showed that both fetuses had de novo idic $(\mathrm{Y})$.

Lange et al. proposed that the SRY gene is often deleted when a break occurs in the short arm of the Y chromosome, and the phenotypes will be mostly female. When a patient presents as female, they might also have signs of Turner syndrome and streak gonads. In contrast, when a patient presents as they might also have symptoms of azoospermia or oligospermia, asthenospermia, hypospadias and cryptorchidism. Some patients also have gender ambiguity and gonadal dysgenesis [12] and others might also be at higher risk for mental retardation and disorders $[11,13]$. Therefore, gender should be determined by ultrasound when prenatal test results show sex chromosome abnormalities in a fetus. Both fetuses described herein had male external genitalia.

The AZF gene located at the distal end of the long arm of Y chromosome was discovered during the 1970s and was later found to be linked to primary azoospermia, severe oligospermia and asthenospermia in males. A microdeletion of AZF is the second leading cause of male infertility, after Klinefelter syndrome [14]. The AZF gene comprises AZFa, AZFb, and the AZFc subregions, and a deletion of one or more of them can cause dyszoospermia. We searched for $\mathrm{Y}$ chromosome deletions by probing six STS within the three regions of the AZF gene [15] and found a deleted $\mathrm{AZFb}+\mathrm{C}$ region and no AZF deletion in fetuses 1 and 2, respectively. Repping et al. proposed that the main cause of a deleted $\mathrm{AZFb}+\mathrm{C}$ region is that the distal P5 and the proximal P4 of the AZFb region share sequence similarity with the P1 of the AZFc region. When the two ends are broken, homologous recombination occurs, then the $\mathrm{AZFb}+\mathrm{C}$ region in the center is lost [16]. A deletion of only the AZFc region has mild effects. This region includes the DAZ multigene family that is deleted in azoospermia. Although azoospermia persists, spermatogenesis can still proceed, and sperm can be detected in the testis. Intracytoplasmic sperm injection (ICSI) allows such patients to have offspring. However, the ability for spermatogenesis is lost when a deletion occurs in AZFb, AZFa, 
or $\mathrm{AZFb}+\mathrm{AZFa}$ regions, and sperm cannot be recovered from the testis $[17,18]$.

The above findings indicated that the karyotype of fetus 1 was mos $45, \mathrm{X}[92] / 46, \mathrm{X},+\mathrm{idic}(\mathrm{Y})(\mathrm{q} 11.21)[8]$, with the 45 , $\mathrm{X}$ cell type being the most prevalent. B-ultrasound detected male external genitalia.

After delivery, fetus 1 could present with symptoms of male Turner syndrome, such as short stature, low intelligence, lack of puberty, primary hypogonadism hypoplasia, and gonadal cytoma(http://ssmc-tl.com/ssmcy-male.html\#si) [19-21]. Furthermore, because the $\mathrm{AZFb}+\mathrm{c}$ region was deleted in this fetus, he would become completely infertile upon reaching adulthood. The fetal karyotype of fetus 2 was mos 45,X[20]/46,X, $+\operatorname{idic}(\mathrm{Y})(\mathrm{q} 11.223)[80]$, with about $21 \mathrm{Mb}$ of repetitive segments in Yp11.3q11.223 of his Y chromosome, which contained the AZF region. Male external genitalia were detected using B-ultrasound. After delivery, this fetus could display the phenotype of XYY syndrome, which is generally normal, except for a possible tendency towards violence or low intelligence. Typical symptoms are not evident during early childhood, and fertility is preserved in adulthood [22]. After genetic counseling provided by Hunan Provincial Maternal and Child Health Care Hospital, the pregnancy of patient 1 was terminated, whereas the fetus of patient 2 was carried to term, delivered, and he has reached the age of 10 months, with normal appearance and growth.

In conclusion, multiple detection strategies should be applied to prenatally distinguish fetuses with congenital malformations or genetic diseases. Moreover, accurate genetic counseling should be provided to reduce the rate of birth defects and improve the health of the population, which is indispensable for prepotency.

\section{Abbreviations \\ AZF: Azoospermia factor; CNV: Copy number variation; DAZ: Deleted in azoospermia; DECIPHER: Database of Chromosomal Imbalance and Phenotype in Humans using Ensembl Resources; DGV: Database of Genomic Variants; FISH: Fluorescence in situ hybridization; ICSI: Intracytoplasmic sperm injection; ISCN: International System for Human Cytogenomic Nomenclature; OMIM: Online Mendelian Inheritance in Man; SNP: Single nucleotide polymorphism; sSMC: Small supernumerary marker chromosome; \\ STS: Sequence-tagged sites; UCSC: University of California Santa Cruz}

\section{Acknowledgments}

Not applicable.

\section{Authors' contributions}

$\mathrm{HS}, \mathrm{XH}$, and WH implemented all tests and drafted the manuscript. PJ and LQ statistically analyzed the data and participated in the design. CJ, WD, HJ, and JZ collected data. HS and WH prepared the original manuscript. XH and WH reviewed and edited the manuscript. All authors read and approved the final version of the manuscript.

\section{Funding}

Funding was received from the Science and Technology Major Project of the Ministry of Science and Technology of Hunan Province, China, grant number: 2017SK1030) and Hunan Provincial Nature Science Foundation, grant number: 2017SK4006).

\section{Availability of data and materials}

All data generated or analyzed are included in this article.

\section{Ethics approval and consent to participate}

All processes and care for the patients followed the Helsinki Declaration and both patients provided written, informed consent to participate in all tests and procedures according to the Ethics Committee at the Maternal and Child Hospital of Hunan Province.

\section{Consent for publication}

Both patients provided written, informed consent to the publication of their innominate details.

\section{Competing interests}

The authors declare that they have no competing interests.

Received: 11 November 2019 Accepted: 15 January 2020

Published online: 11 February 2020

\section{References}

1. An GH, Choi KH, Yang JH, Kim MY, Han JY, Park SY, Lee BY, Lee DE, Ryu HMJJGM: Analysis of parental decisions based on sex chromosome abnormalities detected prenatally: A ten-year update (2001-2010). 2012; $9(1): 17$.

2. Chen XF, Liang L, Fu JF, et al. Study on physique index set for Chinese children andadolescents. Chin J Epidemiol. 2012;33(5):449-54.

3. Reshmi SC, Miller JL, Deplewski D, et al. Evidence of a mechanism for isodicentric chromosome $Y$ formation in a 45,X/46,X,idic(Y)(p11.31)/ 46,X,del(Y)(D11.31)mosaic karyotype. Eur J Med Genet. 2011;54(2):16l-4 https://doi.org/10.1016/j.ejmg.2010.11.002.

4. Liehr T, Mrasek K, Hinreiner S, Reich D, Ewers E, Bartels I, Seidel J, Emmanuil $\mathrm{N}$, Petesen M, Polityko A, et al. Small supernumerary marker chromosomes (sSMC) in patients with a 45,X/46,X,+mar karyotype - 17 new cases and a review of the literature. Sex Dev. 2007;1(6):353-62.

5. lourov IY, Vorsanova SG, Liehr T, Monakhov W, Soloviev IV, Yurov YB. Dynamic mosaicism manifesting as loss, gain and rearrangement of an isodicentric $Y$ chromosome in a male child with growth retardation and abnormal external genitalia. Cytogenet Genome Res. 2008;121(3-4):302-6.

6. Rodriguez L, Liehr T, Mrasek K, Mansilla E, Martinez-Fernandez ML, Garcia A, Martinez-Frias ML. Small supernumerary chromosome marker generating complete and pure trisomy 18p, characterized by molecular cytogenetic techniques and review. Am J Med Genet A. 2007;143a(22):2727-32.

7. Liehr T, Mrasek K. Small Supernumerary Marker Chromosomes (SSMC) in Patients with a 45,X/46,X,+mar Karyotype -17 New Cases and a Review of the Literature. Sex Dev. 2007;1:353-62.

8. Liehr T, Weise Alljomm: Frequency of small supernumerary marker chromosomes in prenatal, newborn, developmentally retarded and infertility diagnostics. 2007;19(5):719-31.

9. Lee $\mathrm{JH}$, Cho HS, Lee ES, Jung BC. A case of partial trisomy 2p23-pter syndrome with trisomy $18 \mathrm{p}$ due to a de novo supernumerary marker chromosome. Korean J Lab Med. 2010;30(3):312-7.

10. Levy B, Wapner RJF, Sterility: Prenatal diagnosis by chromosomal microarray analysis. 2018, 109(2):201-212.

11. Lange J, Skaletsky H, van Daalen SK, Embry SL, Korver CM, Brown LG, Oates RD, Silber S, Repping S, Page DC. Isodicentric Y chromosomes and sex disorders as byproducts of homologous recombination that maintains palindromes. Cell. 2009;138(5):855-69.

12. Lin SY, Lee CN, Peng AY, Yuan TJ, Lee DJ, Lin WH, Ma GC, Chen M. Application of molecular cytogenetic techniques to characterize the aberrant $Y$ chromosome arising de novo in a male fetus with mosaic 45, $\mathrm{X}$ and solve the discrepancy between karyotyping, chromosome microarray, and multiplex ligation dependent probe amplification. J Formos Med Assoc. 2018;117(11):1027-31.

13. Shinawi $M$, Cain MP, Vanderbrink BA, Grignon DJ, Mensing D, Cooper ML, Bader P, Cheung SW. Mixed gonadal dysgenesis in a child with isodicentric $Y$ chromosome: Does the relative proportion of the $45, X$ line really matter? Am J Med Genet A. 2010;152a(7):1832-7.

14. Alimardanian L, Saliminejad K, Razi S, Ahani A. Analysis of partial azoospermia factor $\mathrm{c}$ deletion and DAZ copy number in azoospermia and severe oligozoospermia. Andrologia. 2016;48(9):890-4. 
15. Krausz C, Hoefsloot L, Simoni M, Tuttelmann F. EAA/EMQN best practice guidelines for molecular diagnosis of Y-chromosomal microdeletions: stateof-the-art 2013. Andrology. 2014;2(1):5-19.

16. Repping S, Skaletsky H, Lange J, Silber S, Van Der Veen F, Oates RD, Page DC, Rozen S. Recombination between palindromes P5 and P1 on the human $Y$ chromosome causes massive deletions and spermatogenic failure. Am J Hum Genet. 2002;71(4):906-22.

17. Vogt PH. Genomic heterogeneity and instability of the AZF locus on the human Y chromosome. Mol Cell Endocrinol. 2004;224(1-2):1-9.

18. Hojjati MT, Einollahi N, Nabatchian F, Pourfathollah AA, Mahdavi MR. Allelespecific oligonucleotide polymerase chain reaction for the determination of $\mathrm{Rh} \mathrm{C} / \mathrm{C}$ and Rh E/e antigens in thalassaemic patients. Blood transfusion =. Trasfusione del sangue. 2011;9(3):301-5.

19. Nishi MY, Costa EM, Oliveira SB, Mendonca BB, Domenice $S$. The role of SRY mutations in the etiology of gonadal dysgenesis in patients with $45, X / 46, X Y$ disorder of sex development and variants. Horm Res Paediatr. 2011;75(1):26-31.

20. Jiang $Y$, Wang R, Li L, Xue L, Deng S, Liu R. Molecularcytogenetic study of de novo mosaic karyotype $45, X / 46, X, i(Y q) / 46, X, i d i c(Y q)$ in an azoospermic male: Case report and literature review. Mol Med Rep. 2017;16(3):3433-8.

21. Bruyère $H$, Speevak MD, Winsor EJT, de Fréminville B, Farrell SA, McGowanJordan J, McGillivray B, Chitayat D, McFadden D, Adouard V. Isodicentric Yp: prenatal diagnosis and outcome in 12 cases. Prenat Diagn. 2006;26:324-9.

22. Tuerlings JH, de France HF, Hamers A, Hordijk R, Van Hemel JO, Hansson K, Hoovers JM, Madan K, Van der Blij-Philipsen M, Gerssen-Schoorl KB, et al. Chromosome studies in 1792 males prior to intra-cytoplasmic sperm injection: the Dutch experience. Eur J Hum Genet. 1998;6(3):194-200.

\section{Publisher's Note}

Springer Nature remains neutral with regard to jurisdictional claims in published maps and institutional affiliations.

Ready to submit your research? Choose BMC and benefit from:

- fast, convenient online submission

- thorough peer review by experienced researchers in your field

- rapid publication on acceptance

- support for research data, including large and complex data types

- gold Open Access which fosters wider collaboration and increased citations

- maximum visibility for your research: over $100 \mathrm{M}$ website views per year

At $\mathrm{BMC}$, research is always in progress.

Learn more biomedcentral.com/submissions 